\title{
Short-Term Excess Healthcare Costs Associated with Cardiovascular Events Among Adults with Type 2 Diabetes in Israel: A Retrospective Cohort Study
}

\author{
Cheli Melzer Cohen ${ }^{1}$ (D) Nino Hallén ${ }^{2} \cdot$ Gabriel Chodick $^{1,3} \cdot$ Lotmit Bourvine $^{4} \cdot$ Tal Waner $^{4} \cdot$ Avraham Karasik $^{5}$
}

Accepted: 12 April 2021 / Published online: 27 April 2021

(c) The Author(s) 2021

\begin{abstract}
Objective The aim was to characterise the short-term (up to 12 months) direct economic burden of new cardiovascular (CV) events among adults with type 2 diabetes (T2D) in Israel.

Methods In this retrospective cohort study utilising the electronic health records of the Maccabi Healthcare Services, adults aged $\geq 21$ years with T2D who experienced their first CV event (2013-2016) were identified via adjudicated enrolment in a CV registry. Wilcoxon rank-sum test estimated excess healthcare resource utilisation in three periods after the CV event: immediate ( 1 month; for all patients), acute ( 3 months; for survivors of 1 month of follow-up) and short-term (12 months; for survivors of 3 months of follow-up). Direct healthcare expenditure (2018 United States dollars [USD]) was estimated from unit costs from the State of Israel Ministry of Health price list.

Results In total, 5133 adults experienced a qualifying CV event, with a mean (standard deviation [SD]) age of 67.4 (11.8) years, diabetes duration of 17.7 (11.1) years and glycated haemoglobin of 7.4\% (1.6\%); 38.0\% were female. In USD per patient, mean (SD) immediate costs were $\$ 10,741$ ( $\$ 11,707)$ compared with $\$ 2820$ (\$5661) at baseline (cost ratio [CR] 3.81), acute costs were $\$ 14,586(\$ 15,410)$ compared with $\$ 5202$ ( $\$ 8971)$ at baseline (CR 2.80) and short-term costs were $\$ 23,847$ $(\$ 25,227)$ compared with $\$ 11,123(\$ 15,990)$ at baseline (CR 2.14). A sensitivity analysis of survivors only was consistent with the main analysis.

Conclusions Our results indicate that CV complications of T2D place a substantial excess economic burden on Israel's healthcare system over the short term (up to 12 months).
\end{abstract}

\section{Introduction}

Globally, cardiovascular disease (CVD) is the most common non-communicable disease, responsible for an estimated 17.8 million deaths in 2017, an increase of $21.1 \%$ between 2007 and 2017 [1]. In terms of years of life lost (YLL; a

Cheli Melzer Cohen

melzerco_c@mac.org.il

1 Maccabi Institute for Research and Innovation, Maccabi Healthcare Services, 27 Hamered Street, 68125 Tel Aviv, Israel

2 Novo Nordisk A/S, Søborg, Denmark

3 School of Public Health, Sackler Faculty of Medicine, Tel Aviv University, Tel Aviv, Israel

4 Novo Nordisk A/S - Israel, Kfar Saba, Israel

5 Institute of Endocrinology, Chaim Sheba Medical Center, Tel Hashomer, Israel measure of premature death) on a global scale, ischaemic heart disease (IHD) was ranked as the leading cause of YLL in 2017, while stroke was ranked as the third leading cause of YLL [1]. In Israel, the CVD mortality rate was 187 per 100,000 population in 2010, while the YLL associated with diseases of the circulatory system were 269 per 100,000 population in 2011 [2].

Diabetes confers an approximate twofold increase in CVD risk [3, 4], which is equivalent to that associated with prior chronic heart disease in those with a long duration of diabetes ( $\geq 10$ years) [3]. Due to population growth and ageing, in combination with increased diabetes prevalence, the estimated number of adults with diabetes worldwide has quadrupled in the past 40 years, reaching an estimated 463 million people in 2019 ( $c f .108$ million in 1980) [5, 6], with the vast majority $(\sim 90 \%)$ of cases being type 2 diabetes (T2D) [6]. The age-adjusted prevalence of diabetes in Israel was estimated at $9.7 \%$ in 2019 [6]. CVD is a major cause of morbidity and mortality in people with diabetes, and one of 


\section{Key Points for Decision Makers}

In this database study of adults with type 2 diabetes in Israel, healthcare costs were up to 3.8 times higher after a first cardiovascular (CV) event than in the corresponding time period (baseline) before the event.

The steepest increase in costs was in the immediate period (up to 1 month) after the $\mathrm{CV}$ event compared with baseline in our analysis, which captured costs in patients who survived the $\mathrm{CV}$ events as well as in those who experienced a fatal $\mathrm{CV}$ event.

In addition to previous evidence using different methodologies over longer timescales, decision makers in Israel may find these up-to-date cost estimates useful when evaluating the potential cost savings through implementation of new treatments or strategies to reduce $\mathrm{CV}$ risk in adults with type 2 diabetes.

the largest contributors to healthcare costs [6,7]. Obesity is a risk factor for T2D [8] and an independent risk factor for CVD [9]; thus, it contributes to the economic burden faced by healthcare systems treating patients with T2D and CVD [10].

Given the large clinical burden that CVD places on individuals with $\mathrm{T} 2 \mathrm{D}$ and healthcare systems, international treatment guidelines have recently been updated to provide joint guidance on the management of both diabetes and CVD [11-13]. Furthermore, a number of cardiovascular (CV) outcomes trials have not only demonstrated the CV safety of some glucose-lowering medications, but also the $\mathrm{CV}$ benefit (superiority versus placebo) of certain glucose-lowering medications in individuals with T2D and established CVD or at high/very high CV risk (e.g. [14-17]). In light of these recent findings, the glucagon-like peptide-1 receptor agonists (GLP-1 RAs) and sodium-glucose co-transporter-2 inhibitors (SGLT-2is) with demonstrated CV benefit are now recommended as first- or second-line therapy in people with T2D and either established CVD or at high or very high CV risk $[11,13,18]$. Both the uptake and impact of these treatment guideline updates will be of great interest to policy and decision makers and over the coming years. However, there is a lack of contemporary and comprehensive cost information for CVD in people with T2D to assist healthcare payers and decision makers with an appraisal of the implementation of the new guidelines.

The aim of the present study was to characterise the shortterm (up to 12 months) direct economic burden of new CV events among adults with T2D in Israel.

\section{Methods}

This was a retrospective cohort study of adults with T2D utilising the electronic health records of the Maccabi Healthcare Services (MHS) for the study period 1 January 2012-31 December 2017. The study design received ethics approval from the MHS Institutional Review Board. Individual patient consent was not required due to the anonymised nature of the MHS database.

\subsection{Data Source}

Israel has a statutory national health insurance system, with all permanent residents medically insured by one of four state-mandated, non-profit health maintenance organisations (HMOs) [19]. Data were obtained from the database of the MHS-Israel's second largest HMO, with $~ 2.2$ million active members ( $~ 25 \%$ of Israel's population). The centralised, electronic database includes anonymised, longitudinal data for the MHS members on hospitalisations, healthcare visits, dispensed prescription medications, medical procedures and sociodemographic characteristics. The MHS database also includes several automatically formulated disease-specific registries (e.g. CV, diabetes, hypertension and cancer) that were designed to improve healthcare management and the quality of care for chronic diseases [20]. The CV registry was established in 1998 and includes all MHS members who have been diagnosed at least twice by a hospital or outpatient cardiologist, primary physician and/ or paediatrician, with at least one clinical diagnosis according to the International Classification of Diseases, Ninth Revision [ICD-9] diagnosis coding, or with a relevant Current Procedural Terminology code (Online Resource 1) [20]. Disease registry data are updated daily. The MHS members are broadly representative of Israel's population as a whole, although members tend to be slightly younger with a higher income than the general population $[20,21]$.

\subsection{Study Population}

Adults (aged $\geq 21$ years as of the index date) were included in the study if they had T2D (enrolment in the diabetes registry prior to the index date and not as type 1 diabetes) and experienced their first CV event between 1 January 2013 and 31 December 2016 (enrolment in a CV registry, with no evidence of previous enrolment). The $\mathrm{CV}$ registries considered were IHD or myocardial infarction (MI; including coronary revascularisation procedure); cerebrovascular accident (CVA) or transient ischaemic attack (TIA); peripheral vascular disease (PVD); and heart failure (refer to Online Resource 1). Eligible adults had a minimum of 12 months of data (MHS membership) prior to the index date (date 
of first enrolment in a CV registry). An exclusion criterion was enrolment in the cancer registry after 1 January 2010, based on the assumption that cancer may have a relatively large impact on healthcare resource utilisation (HRU) that might impede the interpretation of associations between $\mathrm{CV}$ events and HRU.

\subsection{Study Periods}

Three study periods after the qualifying CV event were considered: immediate (up to 1 month), acute (up to 3 months) and short term (up to 12 months) for the study population, survivors of 1 and 3 months' follow-up, respectively, compared with the corresponding baseline period (up to 1,3 or 12 months before the qualifying $\mathrm{CV}$ event, respectively).

\subsection{Economic Burden}

Direct healthcare costs and HRU were estimated for various categories of healthcare resources. The healthcare resource categories considered included hospitalisations, healthcare visits (defined as any outpatient visit, excluding hospitalisations and emergency room visits), emergency room visits (excluding those that resulted in a hospitalisation), medical procedures (including laboratory tests and imaging) and dispensed prescription medications. Healthcare resource categories were further broken down as follows: (1) hospitalisations: CV-related (hospitalisation in a cardiology unit or with a recorded $\mathrm{CV}$ procedure), non-CV-related and surgical (hospitalisation in a surgical unit and/or with a recorded surgical procedure); (2) healthcare visits: primary care, cardiologist, diabetologist/endocrinologist, nurse, paramedical (defined as a speech therapist, physiotherapist, dietitian and occupational therapist), social worker and other; (3) medical procedures: laboratory examinations, imaging (CVrelated imaging, non-CV-related, other; $\mathrm{CV}$-related, other; non-CV-related); (4) dispensed prescription medications: CV-related (accepted Anatomical Therapeutic Chemical Classification [ATC] codes), glucose lowering (ATC codes A10), self-measured blood glucose tests and other (e.g. pain, dermatological and corticosteroids). Hospital outpatient visits were categorised as healthcare visits, with the subcategory dependant on the healthcare professional seen. Further details on the classification of healthcare resources as CV-related are available in Online Resource 2.

Unit costs for healthcare resources were derived from the State of Israel Ministry of Health price list [22], converted to 2018 United States Dollars (USD) using a purchasing power parity exchange rate of 3.752 [23], and applied to the HRU estimates. Total costs were the sum of costs for all of the aforementioned healthcare resource categories. Hospitalisation costs were calculated as proportional to the number of days spent in-hospital that fell within the specified study period. For instance, if 10 days of a 15-day hospitalisation took place in the first month after the qualifying $\mathrm{CV}$ event (and 5 days in the second month), immediate costs for this hospitalisation would be calculated as 10/15 multiplied by the hospitalisation cost. Prescription medications were calculated as the number of packets (by items rather than unit dose).

\subsection{Statistical Analysis}

Descriptive statistics were reported for all baseline characteristics, with baseline defined as the most recent recording in the 12-month period prior to the index date. For continuous variables, means \pm standard deviation $(\mathrm{SD})$ were reported. For categorical variables, number (percentage) was reported. For each healthcare resource category, statistical comparisons of HRU between study periods (after the CV event) and the corresponding baseline period (before the CV event) were performed using the Wilcoxon rank-sum test and a two-tailed test; $p<0.001$ was considered statistically significant. Due to a high proportion of patients with zero utilisation of some healthcare resources (e.g. emergency room visits), a Wilcoxon rank-sum test was applied to test for a difference in mean costs between study periods (after the CV event) and the corresponding baseline period (before the $\mathrm{CV}$ event) and a two-tailed test; $p<0.001$ was considered statistically significant. It is worth noting that confidence intervals could not be calculated by the non-parametric Wilcoxon rank-sum test. Analyses were stratified by the qualifying CV event type: IHD and MI (including coronary revascularisation procedure); stroke (defined as CVA and TIA); PVD; or heart failure.

A sensitivity analysis was conducted to compare costs for healthcare resource categories between study periods and the corresponding baseline period for the patients who survived to the end of the respective study period and were not lost to follow-up. Immediate (up to 1 month), acute (up to 3 months) and short-term (up to 12 months) costs were assessed for survivors of 1,3 and 12 months' follow-up, respectively, compared with the corresponding baseline period (up to 1, 3 or 12 months before the qualifying $\mathrm{CV}$ event, respectively).

Analyses were conducted using $\mathrm{SAS}^{\circledR}$ version 9.4 (or later versions; SAS Institute Inc., Cary, NC, USA).

\section{Results}

In total, 5133 patients fulfilled inclusion criteria and were included in the study population (Fig. 1). From the study population, 2893 patients experienced an IHD or MI (including coronary revascularisation procedure), 1049 experienced a CVA or TIA, 646 a new PVD diagnosis and 727 a new 
heart failure diagnosis. In total, 1952 patients (38.0\%) were female, while the study population had a mean \pm SD age of $67.4 \pm 11.8$ years, diabetes duration of $17.7 \pm 11.1$ years, body mass index of $30.5 \pm 5.6 \mathrm{~kg} / \mathrm{m}^{2}$ and glycated haemoglobin of $7.4 \pm 1.6 \%$ (Table 1). Overall, 1155 patients (22.5\%) were current or previous smokers and 3960 (77.1\%) had diagnosed hypertension. In terms of glucose-lowering medications, 3744 patients $(72.9 \%)$ were prescribed metformin, 1225 (23.9\%) insulin, 258 (5.0\%) a GLP-1 RA and $94(1.8 \%)$ an SGLT-2i (Table 1).

\subsection{Healthcare Resource Utilisation}

HRU is presented by study period in Online Resource 3 . Both the number and duration of hospitalisations were significantly elevated after a CV event in comparison with baseline across time scales $(p<0.001$ for all). The mean $\pm \mathrm{SD}$ incremental number of hospitalisations per patient was $0.7 \pm 0.8,0.8 \pm 1.1$ and $1.0 \pm 1.7$ for the immediate, acute and short-term period, respectively, while the incremental duration of hospitalisations per patient was $4.1 \pm 8.1$ days, $6.5 \pm 18.0$ days and $10.2 \pm 43.9$ days, respectively. A similar pattern of elevated HRU after the CV event (relative to baseline) was observed for nearly all other healthcare resources and study periods, including healthcare visits, medical procedures and prescription medications ( $p$ $<0.01$ for all), with only a few exceptions that took place in the immediate period after the event. Exceptions in the immediate period included no significant difference between study periods in the number of laboratory examinations ( $p=$ $0.597)$ or other medical procedures $(p=0.167)$ and significantly fewer imaging procedures after the $\mathrm{CV}$ event relative to baseline $(p<0.001)$. Emergency room visits were rare in the study population during the study, occurring in $0.7 \%$ of patients in the short-term period and in $0.9 \%$ of patients in the corresponding baseline period (Online Resource 4). There was a small but significant difference in favour of greater utilisation of the emergency room at baseline in the immediate period ( $p=0.029$; Online Resource 3). Over the short term (up to 12 months), the mean \pm SD number of additional healthcare resources utilised per patient after the CV event included $8.9 \pm 26.1$ healthcare visits, $4.0 \pm 31.2$ laboratory examinations, $0.5 \pm 3.4$ imaging procedures, 1.9 \pm 13.1 other medical procedures and $21.7 \pm 37.3$ packets of prescription medication, as compared to the corresponding baseline period.

\subsection{Economic Burden}

Total costs across all healthcare resources were elevated in patients for up to 12 months after the CV event, as compared with baseline (Fig. 2). Mean \pm SD immediate costs per patient in USD were $10,741 \pm 11,707$ compared with
$2820 \pm 5661$ at baseline (cost ratio [CR] 3.81, $p<0.001$ ), acute costs were $14,586 \pm 15,410$ compared with $5202 \pm$ 8971 at baseline (CR 2.80, $p<0.001)$ and short-term costs were $23,847 \pm 25,227$ compared with $11,123 \pm 15,990$ at baseline (CR 2.14, $p<0.001$ ). Hospitalisation costs were the key driver of elevated costs, with a large proportion of excess spend in the immediate period after the CV event: mean \pm SD incremental hospitalisation costs per patient were USD $8147 \pm 12,736$, USD $9260 \pm 17,022$ and USD $10,986 \pm 22,539$ in the immediate, acute and short-term periods after the $\mathrm{CV}$ event, respectively. Other relatively important contributors to excess costs after the CV event included prescription medications and healthcare visits, with spend more evenly distributed across the year for these healthcare resources than for hospitalisations. Mean \pm SD incremental costs in USD per patient were $6 \pm 267,140 \pm$ 556 and $531 \pm 1476$ for healthcare visits, alongside $27 \pm$ $608,138 \pm 1797$ and $725 \pm 8475$ for prescription medications, for the immediate, acute and short-term periods, respectively, versus baseline. After an initial period (up to 3 months) of lower costs associated with imaging and other medical procedures after the $\mathrm{CV}$ event, the short-term (up to 12 months) costs associated with these healthcare resources were higher in comparison to baseline. As might be expected by the limited utilisation, there were negligible costs associated with emergency room visits in the study population (Fig. 2).

Figures 3 and 4 present a breakdown of costs by study period for each healthcare resource. In regards to hospitalisations, the incremental spend in favour of the period after the event was equally driven by $\mathrm{CV}$-related and surgical hospitalisations, as well as but to a smaller extent by nonCV-related hospitalisations (Fig. 3a). In the immediate period, mean \pm SD incremental costs in USD per patient were $6724 \pm 12,760,6606 \pm 12,716$ and $1423 \pm 4291$ for $\mathrm{CV}$-related, surgical and non-CV-related hospitalisations, respectively. For healthcare visits (Fig. 3b), the key drivers of the excess short-term spend after the CV event were primary care and other categories. Incremental costs associated with cardiology visits were initially lower than at baseline in the first month after the CV event (USD -15; CR $0.63, p<0.001$ ), before switching to become higher in the period after the CV event over acute (USD 9; CR $1.16, p<0.001$ ) and short-term (USD 75; CR 1.88, $p<$ $0.001)$ timescales. Similar switches were observed for CVrelated imaging and $\mathrm{CV}$-related other medical procedures, whereby utilisation was initially lower than at baseline in the immediate and/or acute periods after the CV event, before reversing to become higher after the event when the short-term period was considered (Fig. 4a). The largest contributor to the excess short-term spend associated with medical procedures was other non-CV-related procedures (mean \pm SD incremental cost per patient USD $263 \pm$ 


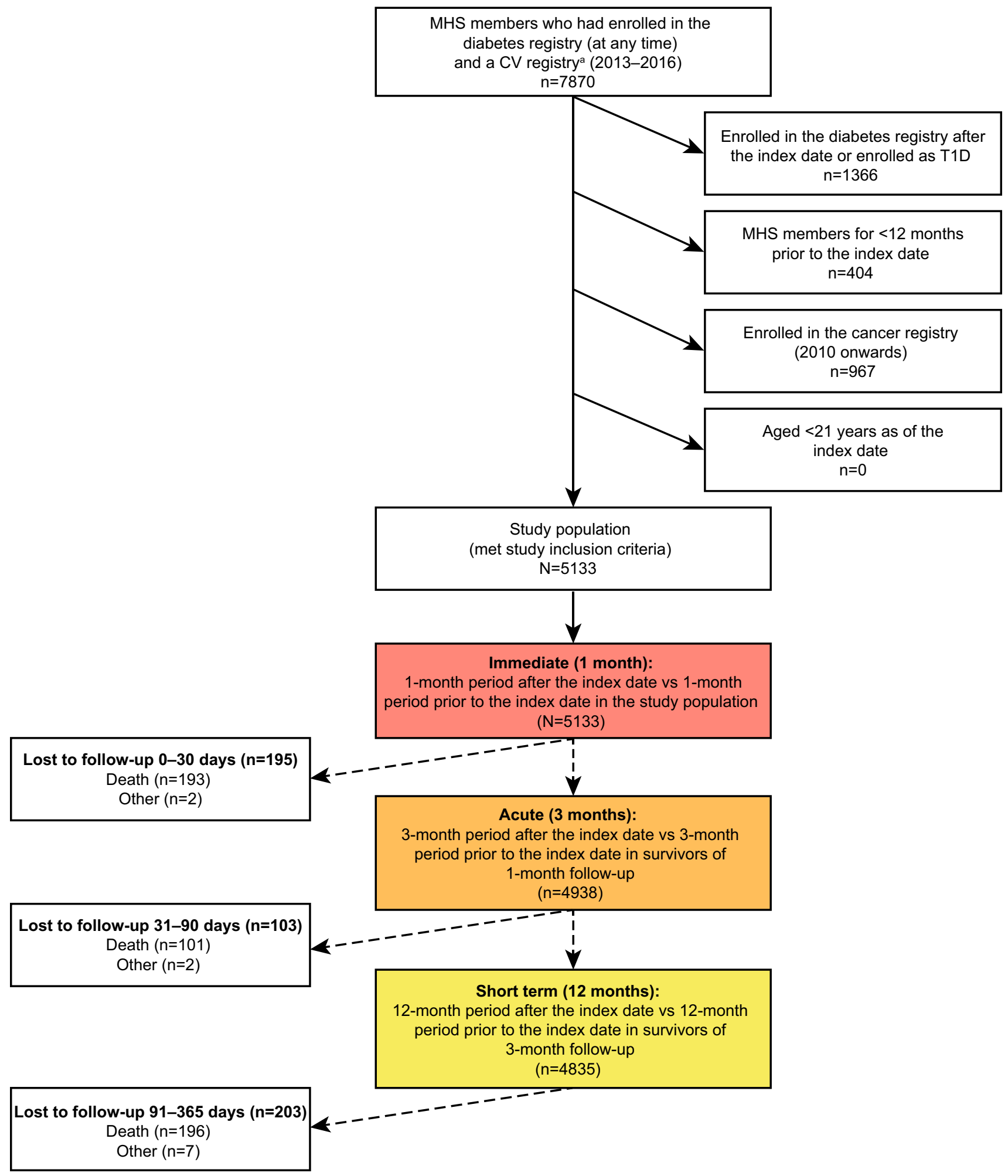

Fig. 1 Patient flow diagram and overview of study periods. The index date was defined as the date of first enrolment in a CV registry. $\mathrm{CV}$ cardiovascular, MHS Maccabi Healthcare Services, $n$ number of patients, $T 1 D$ type 1 diabetes. ${ }^{\text {a }} \mathrm{CV}$ registries considered were ischae- mic heart disease, myocardial infarction (including coronary revascularisation procedure), cerebrovascular accident, transient ischaemic attack, peripheral vascular disease or heart failure. There must be no evidence of prior enrolment in a CV registry 
Table 1 Study population characteristics

\begin{tabular}{|c|c|}
\hline $\begin{array}{l}\text { Characteristic } \\
n(\%) \text { or mean } \pm \mathrm{SD}\end{array}$ & Cohort $(N=5133)$ \\
\hline Female & $1952(38.0)$ \\
\hline \multicolumn{2}{|l|}{ Age, years } \\
\hline Mean \pm SD & $67.4 \pm 11.8(n=5133)$ \\
\hline$<55$ & $793(15.4)$ \\
\hline$\geq 55-<65$ & $1421(27.7)$ \\
\hline$\geq 65-<75$ & $1472(28.7)$ \\
\hline$\geq 75-<85$ & $1039(20.2)$ \\
\hline$\geq 85$ & $408(7.9)$ \\
\hline \multicolumn{2}{|c|}{ Years since inclusion in diabetes registry ${ }^{a}$} \\
\hline Mean \pm SD & $17.7 \pm 11.1(n=5133)$ \\
\hline$\leq 2$ & $745(14.5)$ \\
\hline$>2-\leq 10$ & $2133(41.6)$ \\
\hline$>10$ & $2255(43.9)$ \\
\hline \multicolumn{2}{|c|}{ Socioeconomic status, category } \\
\hline Mean \pm SD & $5.7 \pm 1.9(n=5125)$ \\
\hline $1-3$ & $593(11.6)$ \\
\hline $4-5$ & $1822(35.5)$ \\
\hline $6-8$ & $2217(43.2)$ \\
\hline $9-10$ & $493(9.6)$ \\
\hline \multicolumn{2}{|l|}{ Smoking status } \\
\hline Current smoker & $916(17.8)$ \\
\hline Past smoker & $239(4.7)$ \\
\hline Non-smoker & $2827(55.1)$ \\
\hline Unknown & $1151(22.4)$ \\
\hline \multicolumn{2}{|l|}{ BMI, $\mathrm{kg} / \mathrm{m}^{2}$} \\
\hline Mean \pm SD & $30.5 \pm 5.6(n=4323)$ \\
\hline$<25$ & $632(12.3)$ \\
\hline$\geq 25-<30$ & $1611(31.4)$ \\
\hline$\geq 30-<35$ & $1272(24.8)$ \\
\hline$\geq 35$ & $808(15.7)$ \\
\hline \multicolumn{2}{|l|}{$\mathrm{HbA}_{1 \mathrm{c}}, \%$} \\
\hline Mean \pm SD & $7.4 \pm 1.6(n=4780)$ \\
\hline$<7.0$ & $2364(46.1)$ \\
\hline$\geq 7.0-<8.0$ & $1194(23.3)$ \\
\hline$\geq 8.0-<9.0$ & $563(11.0)$ \\
\hline$\geq 9.0$ & $659(12.8)$ \\
\hline \multicolumn{2}{|l|}{ UACR, mg/g } \\
\hline Mean $\pm \mathrm{SD}$ & $61.4 \pm 99.9(n=4174)$ \\
\hline$\geq 0-<30$ & $2705(52.7)$ \\
\hline$\geq 30-<300$ & $990(19.3)$ \\
\hline$\geq 300$ & $479(9.3)$ \\
\hline \multicolumn{2}{|l|}{$\mathrm{eGFR}, \mathrm{mL} / \mathrm{min} / 1.73 \mathrm{~m}^{2}$} \\
\hline Mean \pm SD & $77.9 \pm 23.2(n=4816)$ \\
\hline$\geq 90$ & $1748(34.1)$ \\
\hline$\geq 60-<90$ & 2032 (39.6) \\
\hline$\geq 45-<60$ & $550(10.7)$ \\
\hline$\geq 30-<45$ & $297(5.8)$ \\
\hline$<30$ & $189(3.7)$ \\
\hline Total cholesterol, mg/dL & $176.3 \pm 46.6(n=4787)$ \\
\hline
\end{tabular}

Table 1 (continued)

\begin{tabular}{ll}
\hline $\begin{array}{l}\text { Characteristic } \\
n(\%) \text { or mean } \pm \mathrm{SD}\end{array}$ & Cohort $(N=5133)$ \\
\hline HDL, mg/dL & $42.2 \pm 11.7(n=4772)$ \\
LDL, mg/dL & $113.7 \pm 64.0(n=4773)$ \\
Triglycerides, mg/dL & $171.1 \pm 142.6(n=4789)$ \\
Glucose-lowering medication $^{\mathrm{b}}$ & \\
Metformin & $3744(72.9)$ \\
DPP-4i & $1324(25.8)$ \\
Sulphonylurea & $1021(19.9)$ \\
GLP-1 RA & $258(5.0)$ \\
SGLT-2i & $94(1.8)$ \\
TZD & $79(1.5)$ \\
Acarbose & $86(1.7)$ \\
Meglitinide $_{\text {Insulin }}$ & $461(9.0)$ \\
Hypertension $^{c}$ & $1225(23.9)$ \\
COPD $^{\mathrm{c}}$ & $3960(77.1)$ \\
\hline
\end{tabular}

Characteristics were the most recent recording in the 12-month period prior to the index date (date of first enrolment into a $\mathrm{CV}$ registry). Socioeconomic status category (1-3) refers to the lowest socioeconomic status and (9-10) refers to the highest socioeconomic status $B M I$ body mass index, $C O P D$ chronic obstructive pulmonary disease, $C V$ cardiovascular, $D P P-4 i$ dipeptidyl peptidase- 4 inhibitor, $e G F R$ estimated glomerular filtration rate, GLP-1 $R A$ glucagon-like peptide-1 receptor agonist, $H b A_{l c}$ glycated haemoglobin, $H D L$ high-density lipoprotein, $L D L$ low-density lipoprotein, $S D$ standard deviation, $S G L T-2 i$ sodium-glucose cotransporter-2 inhibitor, TZD thiazolidinedione, $U A C R$ urine albumin-to-creatinine ratio

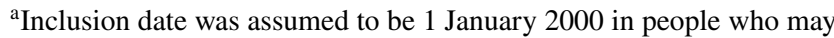
have enrolled before this date

${ }^{\mathrm{b}}$ Dispensed within the 12-month period prior to the index date

${ }^{c}$ Identified through disease-specific registry enrolment

3766). Regarding prescription medications (Fig. 4b), the key driver of the excess short-term spend after the CV event was other medications (i.e. medications that were not taken for a $\mathrm{CV}$ condition, nor were they glucose-lowering). In the short-term period, mean \pm SD incremental costs per patient were USD $80 \pm 238$, USD $74 \pm 416$ and USD 554 \pm 8436 for the categories of $\mathrm{CV}$, glucose-lowering and other medications, respectively.

When patients were stratified by the qualifying CV event type, ratios for total costs were similar across subgroups: total costs were elevated in patients for up to 12 months after the CV event, as compared with baseline, and this was similar across healthcare resources (Online Resource 4). However, there were some differences between subgroups in the utilisation of some healthcare resources between study periods. For instance, in the immediate period after the $\mathrm{CV}$ event, the incremental costs associated with imaging were lower for IHD and MI (USD -101; CR 0.46, $p<0.001$ ), but higher for stroke (USD 


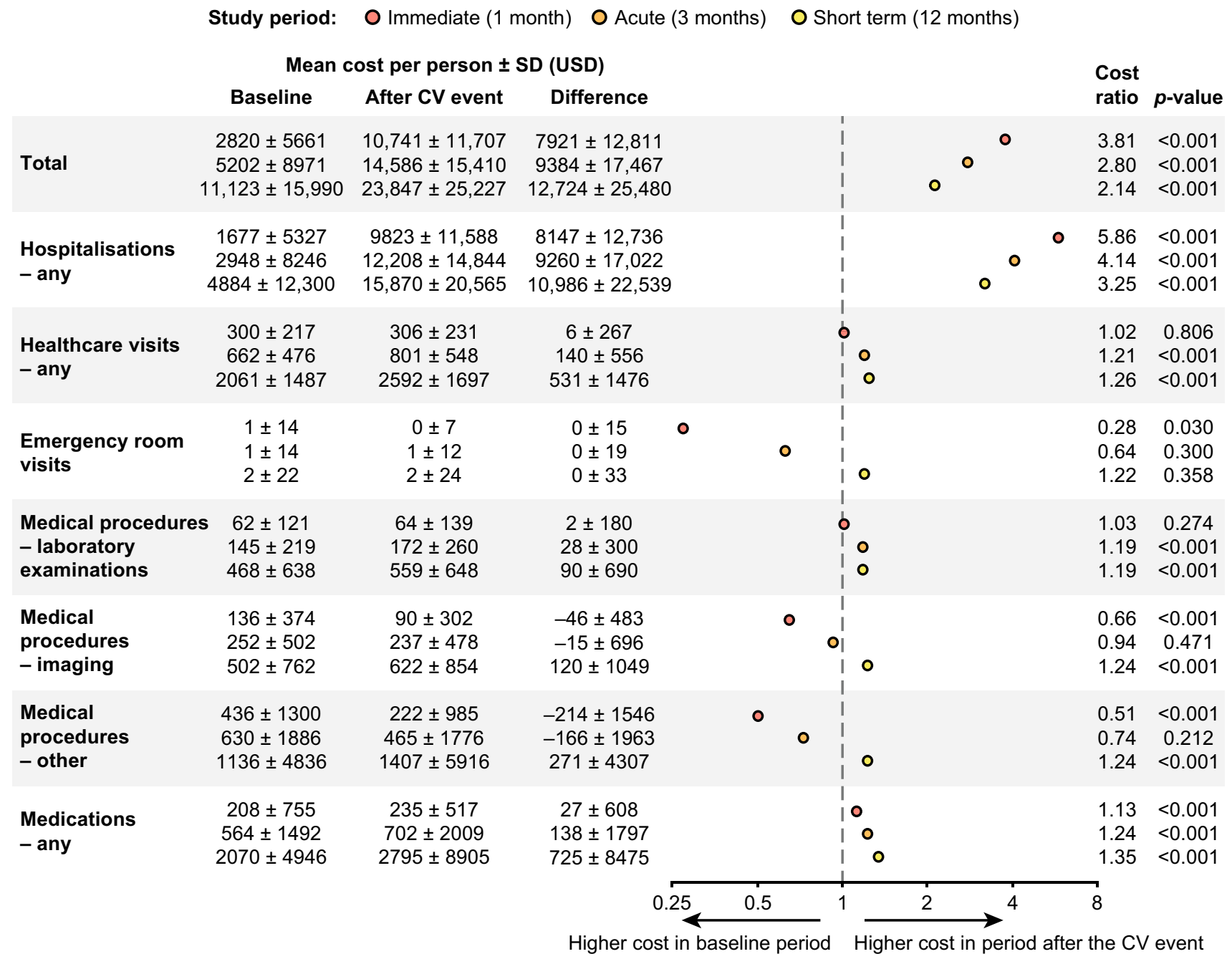

Cost ratio

Fig. 2 Direct healthcare costs in the period after the CV event in comparison with the corresponding baseline period (before the CV event). Differences in mean costs between study periods (after the CV

51; CR 2.07, $p<0.001$ ) than at baseline (Online Resource 5a). Similarly, the incremental costs associated with other medical procedures were lower in the immediate period for IHD and MI (USD -403; CR 0.40, $p<0.001$ ), but not for the other subgroups. In the short term (up to 12 months) after the $\mathrm{CV}$ event, costs associated with prescription medications were only elevated over baseline levels for IHD and MI or stroke, while there was no significant difference between study periods for PVD or heart failure (Online Resource 5c).

Results of the sensitivity analyses including only the survivors of follow-up were all in agreement with the main analysis (Online Resource 6). event) and the corresponding baseline period (before the CV event) were analysed by a Wilcoxon rank-sum test. $C V$ cardiovascular, $S D$ standard deviation, USD United States dollars

\section{Discussion}

Among adults with T2D in Israel, direct healthcare costs were 3.8-, 2.8- and 2.1-fold higher after a new CV event than at baseline in the immediate (up to 1 month), acute (up to 3 months) and short-term (up to 12 months) periods, respectively. Hospitalisation was a key driver of excess HRU and costs after a CV event; additional smaller drivers were primary care and prescription medications for other conditions (not for $\mathrm{CV}$ conditions or glucose-lowering medications). Some categories of CV-related costs were initially lower in the period immediately after a $\mathrm{CV}$ event than at baseline (e.g. visits to a cardiologist, CV-related imaging and $\mathrm{CV}$-related other medical procedures), before switching to incur greater costs after the event over either acute or short-term timescales. 
Study period: O Immediate (1 month) O Acute (3 months) O Short term (12 months)

a

Mean cost per person \pm SD (USD)

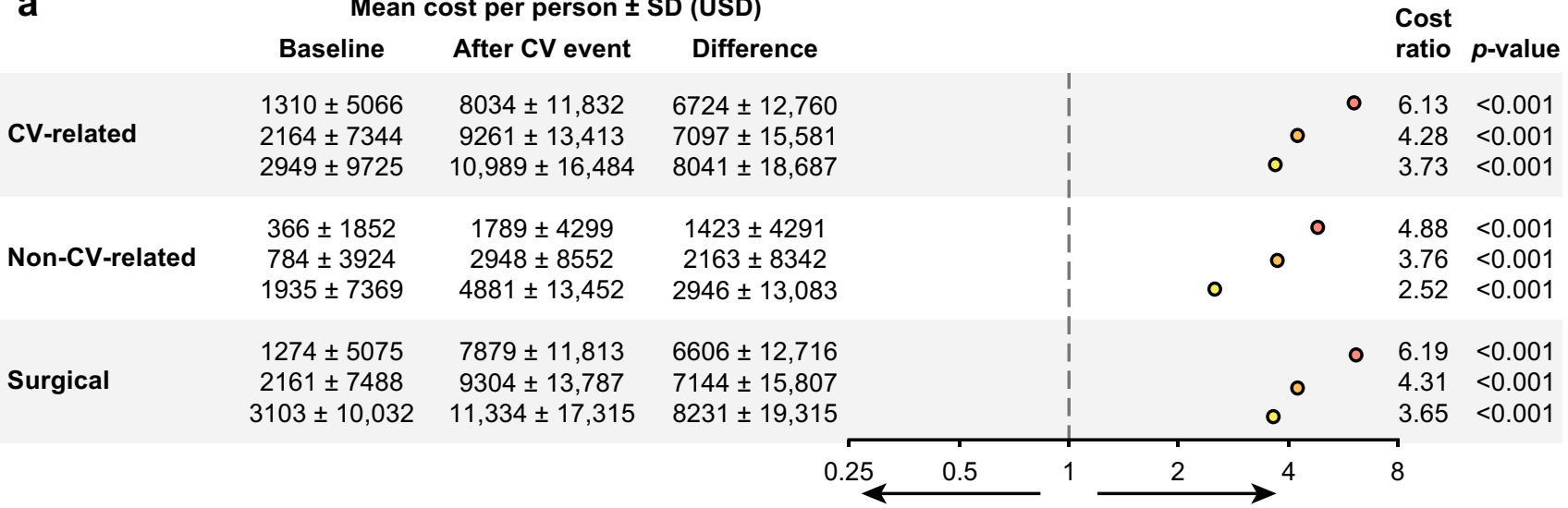

Higher cost in baseline period Higher cost in period after the CV event

Cost ratio

b

\begin{tabular}{|c|c|c|c|}
\hline & Baseline & After CV event & Difference \\
\hline Primary care & $\begin{array}{c}143 \pm 122 \\
331 \pm 244 \\
1060 \pm 714\end{array}$ & $\begin{array}{c}168 \pm 136 \\
413 \pm 288 \\
1300 \pm 811\end{array}$ & $\begin{array}{c}26 \pm 157 \\
82 \pm 291 \\
239 \pm 673\end{array}$ \\
\hline rdiologist & $\begin{array}{c}39 \pm 60 \\
55 \pm 81 \\
85 \pm 129\end{array}$ & $\begin{array}{c}25 \pm 51 \\
64 \pm 94 \\
160 \pm 200\end{array}$ & $\begin{array}{c}-15 \pm 70 \\
9 \pm 111 \\
75 \pm 210\end{array}$ \\
\hline docrinologist & $\begin{array}{c}5 \pm 22 \\
14 \pm 45 \\
52 \pm 128\end{array}$ & $\begin{array}{c}6 \pm 25 \\
17 \pm 65 \\
61 \pm 149\end{array}$ & $\begin{array}{c}1 \pm 30 \\
3 \pm 66 \\
9 \pm 134\end{array}$ \\
\hline se & $\begin{array}{c}20 \pm 37 \\
46 \pm 83 \\
137 \pm 214\end{array}$ & $\begin{array}{c}26 \pm 40 \\
60 \pm 88 \\
182 \pm 244\end{array}$ & $\begin{array}{c}6 \pm 46 \\
15 \pm 98 \\
45 \pm 254\end{array}$ \\
\hline amedical & $\begin{array}{c}8 \pm 33 \\
24 \pm 80 \\
93 \pm 222\end{array}$ & $\begin{array}{c}11 \pm 36 \\
39 \pm 101 \\
133 \pm 300\end{array}$ & $\begin{array}{c}2 \pm 39 \\
15 \pm 114 \\
39 \pm 331\end{array}$ \\
\hline cial worker & $\begin{array}{c}2 \pm 12 \\
4 \pm 23 \\
13 \pm 54\end{array}$ & $\begin{array}{c}3 \pm 15 \\
8 \pm 31 \\
23 \pm 75\end{array}$ & $\begin{array}{l}1 \pm 17 \\
3 \pm 32 \\
9 \pm 74\end{array}$ \\
\hline & $\begin{array}{c}82 \pm 111 \\
187 \pm 250 \\
620 \pm 814\end{array}$ & $\begin{array}{c}68 \pm 110 \\
200 \pm 279 \\
735 \pm 949\end{array}$ & $\begin{array}{c}-15 \pm 122 \\
13 \pm 265 \\
115 \pm 792\end{array}$ \\
\hline
\end{tabular}

(USD)

Cost

ratio $p$-value

$1.18<0.001$

$1.25<0.001$

$1.23<0.001$

$0.63<0.001$

$1.16<0.001$

$1.88<0.001$

$1.12 \quad 0.175$

$\begin{array}{ll}1.21 & 0.005\end{array}$

$1.17<0.001$

$1.28<0.001$

$\begin{array}{lll}0 & 1.32<0.001 \\ 0 & 1.33<0.001\end{array}$

$\begin{array}{lll}0 & 1.32<0.001 \\ 0 & 1.33<0.001\end{array}$

$1.28<0.001$

$0 \quad 1.61<0.001$

○ $1.42<0.001$

o $1.83<0.001$

$0 \quad 1.80<0.001$

- $\quad 1.71<0.001$

$0.82<0.001$

$\begin{array}{ll}1.07 & 0.009\end{array}$

$1.19<0.001$

Higher cost in baseline period Higher cost in period after the CV event

Cost ratio

Fig. 3 Direct healthcare costs in the period after the CV event in comparison with the corresponding baseline period (before the $\mathrm{CV}$ event): breakdown of hospitalisation (a) and healthcare visit (b) costs. Differences in mean costs between study periods (after the CV event) and the corresponding baseline period (before the $\mathrm{CV}$ event) were analysed by a Wilcoxon rank-sum test. $C V$ cardiovascular, $S D$ standard deviation, USD United States dollars 
Study period: O Immediate (1 month) O Acute (3 months) O Short term (12 months)

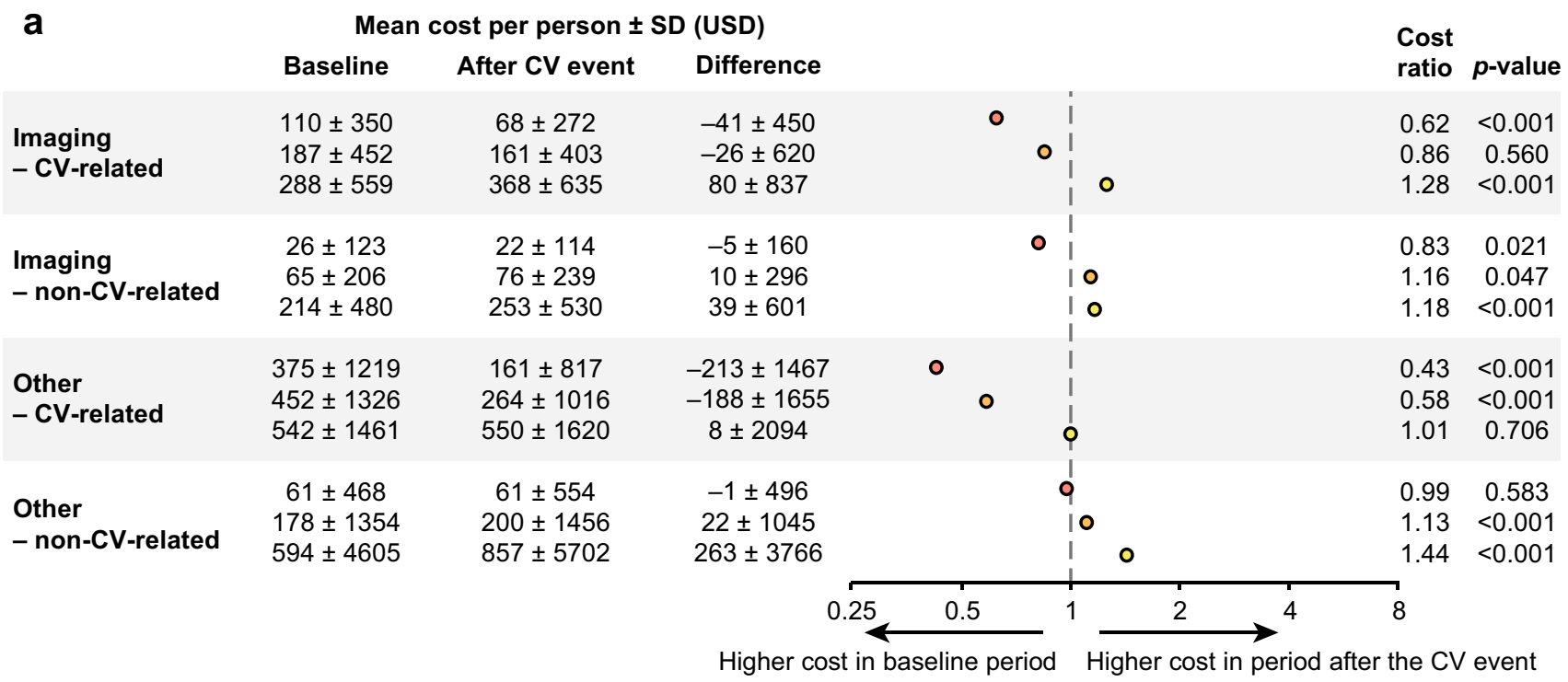

Cost ratio

\begin{tabular}{|c|c|c|c|c|c|c|}
\hline \multirow[t]{2}{*}{ b } & \multicolumn{3}{|c|}{ Mean cost per person \pm SD (USD) } & & \multirow{2}{*}{$\begin{array}{l}\text { Cost } \\
\text { ratio }\end{array}$} & \multirow[b]{2}{*}{$p$-value } \\
\hline & Baseline & After CV event & Difference & & & \\
\hline CV-related & $\begin{array}{c}24 \pm 31 \\
67 \pm 69 \\
259 \pm 265\end{array}$ & $\begin{array}{c}32 \pm 35 \\
90 \pm 78 \\
339 \pm 285\end{array}$ & $\begin{array}{c}8 \pm 40 \\
23 \pm 69 \\
80 \pm 238\end{array}$ & $\begin{array}{l}0 \\
0 \\
0\end{array}$ & $\begin{array}{l}1.32 \\
1.34 \\
1.31\end{array}$ & $\begin{array}{l}<0.001 \\
<0.001 \\
<0.001\end{array}$ \\
\hline Glucose-lowering & $\begin{array}{c}42 \pm 83 \\
124 \pm 198 \\
483 \pm 758\end{array}$ & $\begin{array}{c}46 \pm 89 \\
134 \pm 203 \\
557 \pm 784\end{array}$ & $\begin{array}{c}4 \pm 93 \\
10 \pm 139 \\
74 \pm 416\end{array}$ & $\begin{array}{l}10 \\
0 \\
10 \\
1\end{array}$ & $\begin{array}{l}1.11 \\
1.08 \\
1.15\end{array}$ & $\begin{array}{l}<0.001 \\
<0.001 \\
<0.001\end{array}$ \\
\hline SMBG tests & $\begin{array}{c}9 \pm 25 \\
26 \pm 55 \\
98 \pm 193\end{array}$ & $\begin{array}{c}11 \pm 26 \\
31 \pm 57 \\
116 \pm 200\end{array}$ & $\begin{array}{c}2 \pm 30 \\
4 \pm 51 \\
17 \pm 129\end{array}$ & $\begin{array}{l}0 \\
0 \\
0\end{array}$ & $\begin{array}{l}1.18 \\
1.17 \\
1.18\end{array}$ & $\begin{array}{l}<0.001 \\
<0.001 \\
<0.001\end{array}$ \\
\hline Other & $\begin{array}{c}133 \pm 741 \\
347 \pm 1453 \\
1229 \pm 4745\end{array}$ & $\begin{array}{c}146 \pm 495 \\
447 \pm 1977 \\
1783 \pm 8808\end{array}$ & $\begin{array}{c}13 \pm 586 \\
101 \pm 1774 \\
554 \pm 8436\end{array}$ & $\begin{array}{l}0 \\
0 \\
0\end{array}$ & $\begin{array}{l}1.10 \\
1.29 \\
1.45\end{array}$ & $\begin{array}{l}<0.001 \\
<0.001 \\
<0.001\end{array}$ \\
\hline & & & 0.5 & 1 & 8 & \\
\hline
\end{tabular}

Higher cost in baseline period Higher cost in period after the CV event

Cost ratio

Fig. 4 Direct healthcare costs in the period after the CV event in comparison with the corresponding baseline period (before the $\mathrm{CV}$ event): breakdown of medical procedure costs (a) and medication (b) costs. Differences in mean costs between study periods (after the CV

Our findings complement another recently published real-world MHS study of adults with T2D in Israel who experienced a first $\mathrm{CV}$ event ( $\mathrm{CV}$ group) and who were propensity score-matched to controls without a $\mathrm{CV}$ event (control group) during the 4-year observation period [21]. Over the following 2-year study period, annual direct healthcare costs were $38.9 \%$ higher in the CV group than in the control group, demonstrating that $\mathrm{CV}$ complications event) and the corresponding baseline period (before the CV event) were analysed by a Wilcoxon rank-sum test. $C V$ cardiovascular, $S D$ standard deviation, USD United States dollars

of T2D place substantial economic burden on healthcare systems that persists for 2-6 years after the event [21]. Our findings add to this previous real-world evidence by demonstrating significantly greater utilisation of a wide range of healthcare resources up to 12 months after a new $\mathrm{CV}$ event, in comparison with the preceding 12 months, among adults with T2D in Israel; furthermore, elevated HRU translated into a doubling of direct costs over the 
same period. It is worth noting that our analysis also captured the costs of patients who experienced a fatal CV event or did not survive the study period, in contrast to the majority of analyses. Taken together, these real-world data provide a comprehensive evaluation of costs and demonstrate that CV complications of T2D place a substantial excess economic burden on Israel's healthcare system over both short and longer timescales.

In regards to the global picture, our findings are in alignment with those of a recent systematic literature review of the economic burden of CVD among adults with T2D comprising 24 studies conducted in 13 countries (there were no qualifying studies for Israel) [24]. Einarson et al. [24] reported that the annual direct cost of treating a patient with both CVD and T2D was on average USD 3418-9705 (2016 values reported) higher than treating a patient with T2D alone. Here, we report that mean direct costs increased by USD 12,724 per patient (2018 values reported) in the first year after a new CV event than at baseline among patients with T2D in Israel. A direct comparison of absolute values between studies should be interpreted with caution, as they were derived from countries with different healthcare systems and income levels. However, generally, our findings for Israel do appear to align well with the global picture, adding to growing evidence that CVD among adults with T2D places a substantial economic burden on healthcare systems around the globe. Furthermore, hospitalisation was the key contributor to costs in the systematic review by Einarson and colleagues [24], followed by drugs and outpatient care, which aligns with the major contributors to healthcare costs in our findings for Israel (in rank order): hospitalisations, medications and healthcare visits (particularly the "primary care' and 'other' categories).

The added clinical and economic burden of CVD among individuals with T2D heightens the requirement for healthcare systems to manage the multi-morbid nature of diabetes more effectively. Recent progress has been made with the integration of international treatment guidelines to address the co-management of both diabetes and CVD [11-13]. Furthermore, recent findings from some CV outcomes trials are driving a paradigm shift in recommended T2D management for individuals at high CV risk or with established CVD, with the GLP-1 RAs and SGLT-2is with proven $\mathrm{CV}$ benefit now advocated as either first- or second-line treatment $[11,13,18]$. International guideline updates can take between months and years to filter down into real-world clinical practice, and the present study was conducted prior to the vast majority of the aforementioned updates. As such, our study represents a comprehensive estimate of direct healthcare costs at 'baseline', prior to the updates, that can be monitored over time to assess both the uptake and impact of the guideline updates. In the present study (2013-2016 data), among adults with T2D in Israel, $5.0 \%$ and $1.8 \%$ of the study population were prescribed a glucose-lowering medication from the GLP-1 RA and SGLT-2i classes, respectively, at any time in the 12 months prior to their first CV event. In an observational cohort study, Swedish patients with T2D who had five selected factors (glycated haemoglobin, systolic and diastolic blood pressure, low-density lipoprotein cholesterol, albuminuria and smoking) within therapeutic guideline target ranges had little to no excess risk of death, MI and stroke (albeit with a higher risk of hospitalisation from heart failure) in comparison with matched controls from the general Swedish population [25]. The study by Rawshani and colleagues [25] supports the concept of a multifaceted approach to $\mathrm{CV}$ risk reduction in T2D to reduce the incidence of $\mathrm{CV}$ complications and associated healthcare costs. Future costeffectiveness analyses are desirable in order to evaluate the potential for and scale of cost savings from contemporary evidence-based treatment and multifactorial risk modification in patients with T2D.

The present study has some limitations that should be acknowledged, including those that are inherent to retrospective database analyses. For instance, the data analysed were limited to the data available in the MHS database, while the quality of our findings is dependent on the database quality, with the potential for some errors during database input. All of the costs we report were estimated using the State of Israel Ministry of Health price list and converted to 2018 USD using a purchasing power parity exchange rate. Consequently, our analysis did not account for any fluctuations in direct medical costs over the 6-year study period. Our study also has strengths, namely the MHS database coverage and quality, in addition to the broad representativeness of the MHS members to the general population of Israel. In addition, the generalisability of our results was enhanced by using unit costs for healthcare resources derived from the State of Israel Ministry of Health price list, rather than using the costs to the MHS. Further strengths of the present analysis include the capture of costs for both survivors and non-survivors; the temporal resolution of data, which allowed the detection of granularity in healthcare expenditure within the initial 12-month period after a CV event; and the comparison of costs across study periods for the same patients, whereby each patient acted as their own control, allowing the influence of random between-patient variation in expenditure to be minimised.

To the authors' knowledge, this is the first contemporary and comprehensive assessment of healthcare costs in the initial 12-month period after a new CV event among adults with T2D in Israel. As such, our findings provide important cost information for healthcare payers and policy makers to assist with the evaluation of potential cost 
savings of implementing new interventions and guidelines in Israel.

Our results indicate that $\mathrm{CV}$ complications of T2D place a substantial excess economic burden on Israel's healthcare system over the short term (up to 12 months). Together with previous real-world evidence over longer timescales, our findings highlight the potential for significant cost savings through the initiation of strategies to reduce the $\mathrm{CV}$ risk in adults with $\mathrm{T} 2 \mathrm{D}$.

Supplementary Information The online version contains supplementary material available at https://doi.org/10.1007/s41669-021-00268-5.

Acknowledgements The authors would like to thank the participants of the study. The authors acknowledge the contributions of Ilan Tsitsianov and Aliza Hammerman Rozenberg to the statistical analyses. Medical writing support was provided by Anna Campbell $(\mathrm{PhD})$ and editorial assistance was provided by Izabel James (MBBS), of Watermeadow Medical, an Ashfield company, part of UDG Healthcare plc, funded by Novo Nordisk.

\section{Declarations}

Funding This study and the article processing charges were funded by Novo Nordisk A/S.

Conflict of interest $\mathrm{CMC}$ and GC have no conflict of interest to report. $\mathrm{NH}, \mathrm{LB}$ and TW are all employees of Novo Nordisk. AK has received research grants, honoraria for lectures and consulting fees from Novo Nordisk.

Ethics approval The study design was approved by the Maccabi Healthcare Services' Institutional Review Board.

Consent to participate Individual patient consent was not required due to the anonymised nature of the Maccabi Healthcare Services' database.

Data availability statement The datasets generated and/or analysed during the current study are available from the corresponding author on reasonable request.

Related manuscript None of the authors have a related or duplicate manuscript under consideration or accepted for publication elsewhere.

Previous presentation Some parts of this study were presented as a poster at the 23rd Annual European Congress of the International Society for Pharmacoeconomics and Outcomes Research, 16-19 November 2020.

Author contributions $\mathrm{CMC}$ is the guarantor of this work and, as such, had full access to all the data in the study, and takes responsibility for the integrity of the data and the accuracy of the data analysis. All authors confirm that they meet the International Committee of Medical Journal Editors (ICJME) uniform requirements for authorship and that they have contributed to critical analysis and interpretation of the data, drafting and/or critically revising the article and sharing in the final responsibility for the content of the manuscript, as well as the decision to submit it for publication.
Open Access This article is licensed under a Creative Commons Attribution-NonCommercial 4.0 International License, which permits any non-commercial use, sharing, adaptation, distribution and reproduction in any medium or format, as long as you give appropriate credit to the original author(s) and the source, provide a link to the Creative Commons licence, and indicate if changes were made. The images or other third party material in this article are included in the article's Creative Commons licence, unless indicated otherwise in a credit line to the material. If material is not included in the article's Creative Commons licence and your intended use is not permitted by statutory regulation or exceeds the permitted use, you will need to obtain permission directly from the copyright holder. To view a copy of this licence, visit $\mathrm{http} / / /$ creativecommons.org/licenses/by-nc/4.0/.

\section{References}

1. GBD 2017 Causes of Death Collaborators. Global, regional, and national age-sex-specific mortality for 282 causes of death in 195 countries and territories, 1980-2017: A systematic analysis for the Global Burden of Disease Study 2017. Lancet. 2018;392(10159):1736-88.

2. OECD. Cardiovascular Disease and Diabetes: Policies for Better Health and Quality of Care. Country Note-Israel. OECD Health Policy Studies 2015 [accessed Dec 2020]; http://www.oecd.org/ health/cardiovascular-disease-and-diabetes-policies-for-betterhealth-and-quality-of-care-9789264233010-en.htm

3. Rana JS, Liu JY, Moffet HH, Jaffe M, Karter AJ. Diabetes and prior coronary heart disease are not necessarily risk equivalent for future coronary heart disease events. J Gen Intern Med. 2016;31(4):387-93.

4. Sarwar N, Gao P, Seshasai SR, Gobin R, Kaptoge S, Di Angelantonio E, et al. Diabetes mellitus, fasting blood glucose concentration, and risk of vascular disease: a collaborative meta-analysis of 102 prospective studies. Lancet. 2010;375(9733):2215-22.

5. NCD Risk Factor Collaboration (NCD-RisC). Worldwide trends in diabetes since 1980: A pooled analysis of 751 population-based studies with 4.4 million participants. Lancet. 2016;387(10027):1513-30.

6. International Diabetes Federation. IDF Diabetes Atlas. 9th ed. Brussels: International Diabetes Federation; 2019.

7. Hex N, Bartlett C, Wright D, Taylor M, Varley D. Estimating the current and future costs of type 1 and type 2 diabetes in the UK, including direct health costs and indirect societal and productivity costs. Diabet Med. 2012;29(7):855-62.

8. Schnurr TM, Jakupović H, Carrasquilla GD, Ängquist L, Grarup $\mathrm{N}$, Sørensen TIA, et al. Obesity, unfavourable lifestyle and genetic risk of type 2 diabetes: a case-cohort study. Diabetologia. 2020;63(7):1324-32.

9. Barroso TA, Marins LB, Alves R, Gonçalves ACS, Barroso SG, Rocha GdSJJJoCS. Association of central obesity with the incidence of cardiovascular diseases and risk factors. Int J Cardiovasc Sci. 2017;30(5):416-24.

10. Tremmel M, Gerdtham UG, Nilsson PM, Saha S. Economic Burden of Obesity: A Systematic Literature Review. International journal of environmental research and public health. 2017;14(4).

11. Cosentino F, Grant PJ, Aboyans V, Bailey CJ, Ceriello A, Delgado V, et al. 2019 ESC Guidelines on diabetes, pre-diabetes, and cardiovascular diseases developed in collaboration with the EASD. Eur Heart J. 2020;41(2):255-323.

12. American Diabetes Association. 10. Cardiovascular disease and risk management: Standards of medical care in diabetes-2020. Diabetes Care. 2020;43(Suppl 1):S111-S34. 
13. Arnett DK, Blumenthal RS, Albert MA, Buroker AB, Goldberger $\mathrm{ZD}$, Hahn EJ, et al. 2019 ACC/AHA Guideline on the primary prevention of cardiovascular disease: Executive summary: A report of the American College of Cardiology/American Heart Association Task Force on Clinical Practice Guidelines. Circulation. 2019;140(11):e563-95.

14. Marso SP, Daniels GH, Brown-Frandsen K, Kristensen P, Mann JF, Nauck MA, et al. Liraglutide and cardiovascular outcomes in type 2 diabetes. N Engl J Med. 2016;375(4):311-22.

15. Gerstein HC, Colhoun HM, Dagenais GR, Diaz R, Lakshmanan $\mathrm{M}$, Pais P, et al. Dulaglutide and cardiovascular outcomes in type 2 diabetes (REWIND): a double-blind, randomised placebo-controlled trial. Lancet. 2019;394(10193):121-30.

16. Neal B, Perkovic V, Mahaffey KW, de Zeeuw D, Fulcher G, Erondu N, et al. Canagliflozin and cardiovascular and renal events in type 2 diabetes. N Engl J Med. 2017;377(7):644-57.

17. Zinman B, Wanner C, Lachin JM, Fitchett D, Bluhmki E, Hantel $\mathrm{S}$, et al. Empagliflozin, cardiovascular outcomes, and mortality in type 2 diabetes. N Engl J Med. 2015;373(22):2117-28.

18. American Diabetes Association. 9. Pharmacologic approaches to glycemic treatment: Standards of medical care in diabetes-2020. Diabetes Care. 2020;43(Suppl 1):S98-S110.

19. Rosen B, Waitzberg R, S M. Israel: Health system review. Health Systems in Transition. 2015;17(6):1-212.
20. Shalev V, Chodick G, Goren I, Silber H, Kokia E, Heymann AD. The use of an automated patient registry to manage and monitor cardiovascular conditions and related outcomes in a large health organization. Int J Cardiol. 2011;152(3):345-9.

21. Melzer Cohen C, Hallén N, Chodick G, Bourvine L, Waner T, Karasik A. Elevated costs and healthcare resource utilization in patients with type 2 diabetes and established cardiovascular disease in Israel. Value Health Reg Issues. 2020;22:83-92.

22. State of Israel Ministry of Health. Price list for ambulatory and hospitalization services. 2018; https://www.health.gov.il/English/ Topics/finance/Pages/default.aspx. Accessed Nov 2019.

23. Organization for Economic Cooperation and Development. Purchasing power parities (PPP). 2018; https://data.oecd.org/conve rsion/purchasing-power-parities-ppp.htm. Accessed Sep 2019.

24. Einarson TR, Acs A, Ludwig C, Panton UH. Economic burden of cardiovascular disease in type 2 diabetes: a systematic review. Value Health. 2018;21(7):881-90.

25. Rawshani A, Rawshani A, Franzén S, Sattar N, Eliasson B, Svensson AM, et al. Risk factors, mortality, and cardiovascular outcomes in patients with type 2 diabetes. N Engl J Med. 2018;379(7):633-44. 